\title{
Effect of acid-assisted hydrothermal carbonization (HTC) process of tree branches using nitric acid on cadmium adsorption
}

\author{
Reza Khoshbouy $^{1, *}$, Rico Lejiu ${ }^{1, *}$, Fumitake Takahashi ${ }^{1}$, and Kunio Yoshikawa ${ }^{1}$ \\ ${ }^{1}$ Department of Transdisciplinary Science and Engineering, Graduate School of Environment and Society, Tokyo Institute of \\ Technology, Yokohama 226-8502, Japan
}

\begin{abstract}
Application of acid in HTC process has been confirmed to have effect on hydrochar properties related to its adsorption capacity. Woody materials (tree branches) were used to investigate the relation of nitric acid addition in HTC process on the hydrochar surface properties and its adsorption mechanism toward cadmium in water solution. Tree branches were processed at $200-260{ }^{\circ} \mathrm{C}$ mixed with water and nitric acid $\left(\mathrm{HNO}_{3}\right)$ at ratio $0-50 \%$ to hydrochar mass and held for holding time of 30, 105 and 180 minutes. Batch adsorption test was conducted by mixing the hydrochars with cadmium solution at $100 \mathrm{ppm}$ and shaken for 24 hours at room temperature. The BET surface area, oxygen functional group (OFG) and the exchanged cations were analysed to investigate the effect of HTC process condition, nitric acid addition, and adsorption mechanism of cadmium. Tree branches treated at $200{ }^{\circ} \mathrm{C}$ for 30 minutes and acid ratio of $50 \%$ showed the best adsorption result. Analysis on the surface properties also showed the best condition for cadmium adsorption. Thus hydrothermal treatment condition at low temperature, short time and high acid ratio usage could be effective in removing cadmium from water. The cadmium adsorption by cation exchange interaction might be the major adsorption mechanism as shown by consistency of trend of the exchanged cation concentration with cadmium adsorption capacity.
\end{abstract}

\section{Introduction}

Development of world industries have been causing environmental issue on surface water in the world recently. Particularly, heavy metal pollution is one of the biggest issue of wastewater produced by industries. Heavy metal in water have toxic properties and may cause health impact on bio-organism, and it may also accumulate inside them. Due to its hazard effects, water contaminated with heavy metals must be treated to ensure water security for living environment [11].

Many water treatment method have been tested, and adsorption is one of the most effective and low-cost approach to remove heavy metals from water among others. Carbon-based materials have been proved as the most effective adsorbent to remove pollutant from wastewater [2]. Currently many researches are conducted to produce effective and low-cost adsorbent in removing heavy metal from wastewater. Hydrochar is one of among adsorbent materials that is applicable in heavy metal adsorption, and proved to have potential as effective heavy metal adsorbent materials [12, 16, 18]. Hydrochar is produced by utilizing hydrothermal carbonization (HTC) process using water media and low temperature [7]. HTC is commonly applied to wet biomass, such as algae, tree waste, and food waste due to its process which utilize water. Therefore it is more beneficial that other thermal treatment such as pyrolysis, which require dry material and more energy to process wet materials [4]. Moreover, application of low temperature also makes HTC have higher average solid yield than pyrolysis [3].

Hydrochars were suspected to have good capabilities in adsorbing heavy metals due to its surface properties, similarly to biochars. Physicochemical properties of biochar surface significantly affect its capabilities to adsorb heavy metals [8]. This is also proved by analysis on adsorption mechanism of hydrochar on heavy metals, such as cation exchange, precipitation and cation- $\pi$ interaction [18]. However, related researches proved that each heavy metals have their own distinctive adsorption mechanism on either hydrochar or biochar. Based on research by Zhou et al. [18], chromium (VI) adsorption was majorly influenced by the interaction with surface functional group. Different research with lead was conducted by Ding et al. [5] and Lu et al. [9] reporting that cation exchange is the main mechanism for lead adsorption by biochar. Knowing possible adsorption

Corresponding author: lejiu.r.aa@m.titech.ac.jp 
mechanism of hydrochar and heavy metal is important in determining important surface properties to enhance its adsorption capacity and deciding the suitable process.

HTC process was modified in this research by adding nitric acid $\left(\mathrm{HNO}_{3}\right)$ to assist hydrothermal process. Several similar studies have been conducted to investigate effect of acid addition on hydrochar. Tang et al. [13] applied $\mathrm{H}_{3} \mathrm{PO}_{4}$ solution by soaking biogas residues with it and left overnight before doing HTC process. Similar method was also applied on banana peels hydrochar at various concentration [18]. Another method was conducted by Jain et al. [10] using $\mathrm{H}_{2} \mathrm{O}_{2}$ acid through several variety of steps by adding acid during HTC process. The purpose of adding acid is because it has been reported that acid has abilities to enhance surface properties of hydrochar in terms of heavy metal adsorption, such as pore size, functional group and surface cations $[1,14]$.

This research was conducted by adding $\mathrm{HNO}_{3}$ during HTC process. The acid addition was varied by using several concentration of acid. The main objective of this research was to evaluate cadmium adsorption by hydrochar derived from wood material with value-added properties using acid-assisted process. The specific objectives were: (1) to analyse effect of acid addition for HTC process condition on hydrochar adsorption for heavy metals, (2) to find the main adsorption mechanism for cadmium, and (3) to compare the adsorption capacity of tree branches-derived hydrochar with commercial activated carbon.

\section{Materials and methods}

\subsection{Chemicals}

Heavy metal solutions were prepared from cadmium (Cd) salt $\left(\mathrm{Cd}\left(\mathrm{NO}_{3}\right)_{2} \cdot 4 \mathrm{H}_{2} \mathrm{O}\right)$ diluted with deionized water at concentration of $100 \mathrm{ppm}$. Acid $(\mathrm{HCl})$ and base $(\mathrm{NaOH})$ solution were used for Boehm titration were prepared at $0.05 \mathrm{~mol} / \mathrm{L}$ concentration. Strong acid solution $\left(\mathrm{HNO}_{3}\right)$ with $70 \%$ concentration were prepared as mixture for the HTC process.

\subsection{Hydrochar production}

Tree branches were collected from local farmers in Japan and used as feedstock for hydrochar production. About 4 $\mathrm{g}$ of air-dried tree branches were mixed with $20 \mathrm{~mL}$ of deionized water and acid $\left(\mathrm{HNO}_{3}\right)$ at determined ratio to feedstock mass $(0 \%, 25 \%$ and $50 \%)$, then added into 50 $\mathrm{mL}$ stainless steel autoclave. Then reactor was sealed and enclosed partially with insulator, then heated up to temperature of 200,230 , and $260{ }^{\circ} \mathrm{C}$. The reactor was held at determined temperature with time variety of 30 , 105 , and 180 minutes. After the process, the reactor was cooled down to room temperature and the solid product was collected by filtration using set of filter paper, funnel and vacuum pump. During filtration, washing was conducted with Deionized water (DW) to reduce the acidity of the char that is caused by the acid added into the process. The hydrochar was then dried in oven at 105
${ }^{0} \mathrm{C}$ for 24 hours, then collected and stored in the glass bottle for further analysis. Fig. 1 shows the overall experimental design of this research

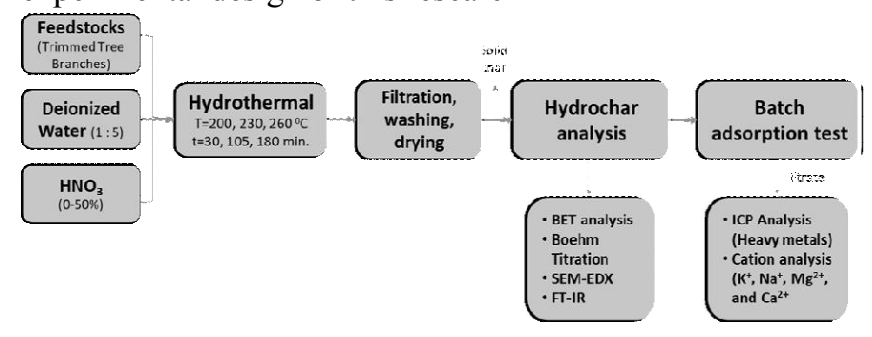

Fig. 1. Experimental design

The experiment design for this research used 11 different treatment condition. The utilization of this experiment design was for finding the optimal HTC process condition and to investigate the effect of acid addition compared to the non-added process. The detail is described in the table below.

Table 1. Hydrothermal Process Condition Variation.

\begin{tabular}{|c|c|c|c|}
\hline $\begin{array}{c}\text { Sample } \\
\text { code }\end{array}$ & $\begin{array}{c}\text { Temperature } \\
\mathbf{(} \mathbf{C})\end{array}$ & $\begin{array}{c}\text { Holding } \\
\text { time (min.) }\end{array}$ & $\begin{array}{c}\text { Acid Ratio } \\
\mathbf{( \% )}\end{array}$ \\
\hline TB-01 & 200 & 30 & 0 \\
\hline TB-02 & 200 & 30 & 50 \\
\hline TB-03 & 200 & 180 & 0 \\
\hline TB-04 & 200 & 180 & 50 \\
\hline TB-05 & 230 & 105 & 0 \\
\hline TB-06 & 230 & 105 & 50 \\
\hline TB-07 & 260 & 30 & 0 \\
\hline TB-08 & 260 & 30 & 50 \\
\hline TB-09 & 260 & 180 & 0 \\
\hline TB-10 & 260 & 180 & 50 \\
\hline TB-11 & 230 & 105 & 25 \\
\hline
\end{tabular}

Commercial activated carbon (CAC) were obtained in two different forms, powdered and granular. Both CAC have similar properties with different surface area. CAC has been commonly used for organic pollutant removal. In this research, selected CAC was compared with produced hydrochars regarding its cadmium adsorption capacity to investigate to potential of hydrochar to substitute CAC as heavy metal adsorbent.

\subsection{Characterization of hydrochar}

Analysis applied for the raw feedstock and its hydrochar were including BET surface area, elemental composition (C, H, and $\mathrm{O}$ ), Boehm titration, and heavy metal removal efficiency. The specific surface area was determined by the Brunauer-Emmet-Teller (BET) method. The elemental contents and ratio were analysed using elemental analyser (Vario Micro Cube, Elementar, Germany). Cadmium adsorption by hydrochars was analysed using the Inductively Couple Plasma-Mass Spectrophotometry (ICP-MS) after adsorption batch test. Effect of hydrochar on water was investigated by mixing 
$0.1 \mathrm{~g}$ hydrochar with $25 \mathrm{~mL} \mathrm{DW}$, and then shaken for 24 hours using mechanical shaker at $25{ }^{0} \mathrm{C}$ along with a blank sample. The acidity of solution after adsorption was analysed using the $\mathrm{pH}$ meter. ICP-MS was also used to analyse the content of released cations $\left(\mathrm{K}^{+}, \mathrm{Na}^{+}, \mathrm{Ca}^{2+}\right.$, and $\left.\mathrm{Mg}^{2+}\right)$ after adsorption process. Scanning Electron Microscope (SEM) was conducted to investigate the surface physical state before and after application of acid in respective process condition. Fourier Transform Infrared (FTIR) was utilized to observe the crystal structure and the component of organic groups of the samples before and after cadmium adsorption test.

\subsection{Batch adsorption experiments}

Batch adsorption experiments were conducted by mixing $0.1 \mathrm{~g}$ of hydrochar with $25 \mathrm{~mL}$ cadmium solution with concentration of $100 \mathrm{mg} \mathrm{L}^{-1}$. The mixture was then shaken for 24 hours at $140 \mathrm{rpm}$ and kept at $25{ }^{\circ} \mathrm{C}$ along with one blank sample. Afterwards, the mixtures were filtered with vacuum to separate the hydrochar from solution. Both the filtrate and hydrochar were kept for later analyses. The filtrates were analysed with the ICPMS to determine the quantity of cadmium after adsorption process and the released cations. While the stored hydrochars were dried and will be analysed with FTIR and SEM.

The adsorption capacity Q $\left(\mathrm{mg} \cdot \mathrm{g}^{-1}\right)$ and the removal efficiency percentage $(\%$ removal $)$ were calculated with the following equations:

$$
\begin{gathered}
Q=\frac{\left(C_{0}-C_{\theta}\right) \times v}{m} \\
\text { \%removal }=\frac{\left(C_{o}-C_{o}\right)}{C_{O}} \times 100 \%
\end{gathered}
$$

where $\mathrm{C}_{0}$ and $\mathrm{C}_{\mathrm{e}}$ are the initial heavy metal and the equilibrium concentration $\left(\mathrm{mg} . \mathrm{L}^{-1}\right)$, respectively. $\mathrm{V}$ is the volume of solution (L) and $\mathrm{m}$ is the weight of hydrochar $(\mathrm{g})$.

\section{Results and discussion}

\subsection{Physicochemical properties of tree branches-derived hydrochar}

The solid yields from HTC process of tree branches were $28.92-59.65 \%$. The results were still comparable with general HTC process yield on woody biomass. Several condition which used acid in its process has lower solid yield compared to process without acid addition. This was the result of $\mathrm{HNO}_{3}$ addition which caused increase on degree of carbonization to the feedstocks. Other samples which were processed with high temperature produced hydrochar with the physical characteristic of black colour, finer particles, and less yields. Compared to condition with lower temperature, the hydrochars were showing dark brown colour and had higher solid yield. This characteristic was also affected by addition of acid due to higher degree of carbonization. Moreover, the particle size was coarser and more difficult to grind compared to hydrochar produced with less temperature. At temperature of $230{ }^{0} \mathrm{C}$, addition of acid helps the carbonization process and caused the hydrochar to become finer and have darker colour. However at 200 ${ }^{0} \mathrm{C}$, addition of nitric acid did not have much effect on the visual appearance of hydrochar compared to sample without acid. Addition of acid might have higher effect at high temperature process. The highest solid yields were TB-01 (58.17\%) and TB-03 (59.65\%), which processed with lowest temperature and without addition of acid. The time variation did not show much difference on hydrochar yield, like shown by results of TB-01 and TB-03. Fig. 2 shows the hydrochar yields of all sample conditions.

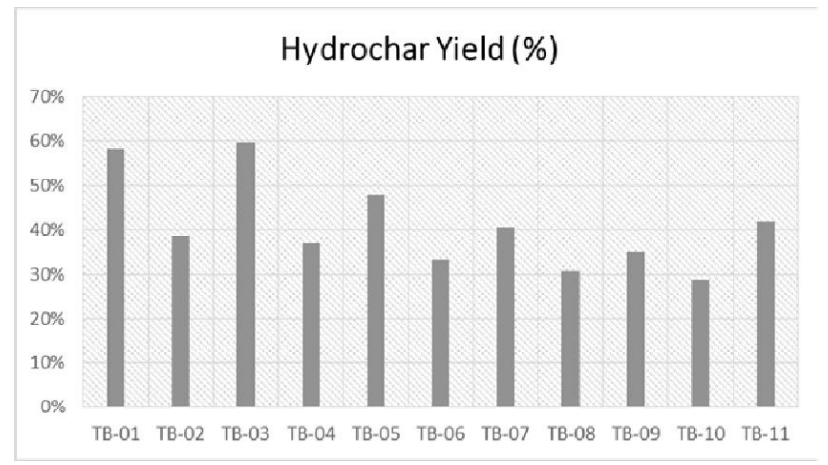

Fig. 2. Hydrochar yields of hydrothermal process

The overall BET surface area after HTC process were showed in Fig. 3. The highest surface area was gained from TB-03. The result shows that hydrochar processed with low temperature and no acid condition $\left(\mathrm{T}=200{ }^{\circ} \mathrm{C}\right.$, $\mathrm{t}=180 \mathrm{~min}$., acid $=0 \%$ ) could produce hydrochar with high BET surface area. The result was also comparable with TB-01 which used less time for its process. This result shows that time variation for this hydrothermal process did not affect surface area value of hydrochar. Therefore time variation might be neglected for variation of hydrothermal treatment condition. Based on experiment by Zhou et al. [18], higher concentration of acid applied in HTC process should produce hydrochar with less BET surface area. However, in this experiment the addition of acid showed both increase and decrease trends between process with and without addition of acid. There might be possibilities that the difference in method of acid application could cause different effects on surface area of hydrochar. The error of results could 


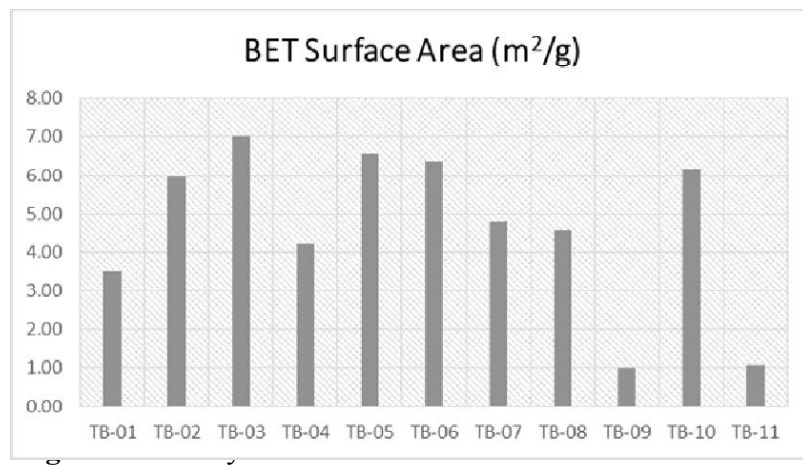

also be caused by physical characteristics of the hydrochars. Several samples which utilized low temperature and low acid have coarser and harder particles compared to hydrochars with high temperature. This might affects the BET analysis results.

\subsection{Effect of $\mathrm{HNO}_{3}$ on hydrochar cadmium adsorption and its mechanism}

The adsorption capacity of cadmium were examined by mixing each $0.1 \mathrm{~g}$ hydrochar with $25 \mathrm{~mL}$ cadmium solution with concentration of $100 \mathrm{mg} . \mathrm{L}^{-1}$. The removal efficiency results are shown in Fig. 4. The highest cadmium removal is shown by TB-02 at $16.97 \%$ removal. This result shows that the utilization of low temperature, short time, and high acid ratio could produce hydrochar with high cadmium adsorption capacity. In general, the hydrochar samples with acid addition shows higher cadmium removal compared to similar process condition without adding acid, such as TB-07 (11.94\%) to TB-08 (14.92\%). The main factors of its high cadmium removal was investigated by exchanged cation content, OFG and BET surface area of the hydrochars.

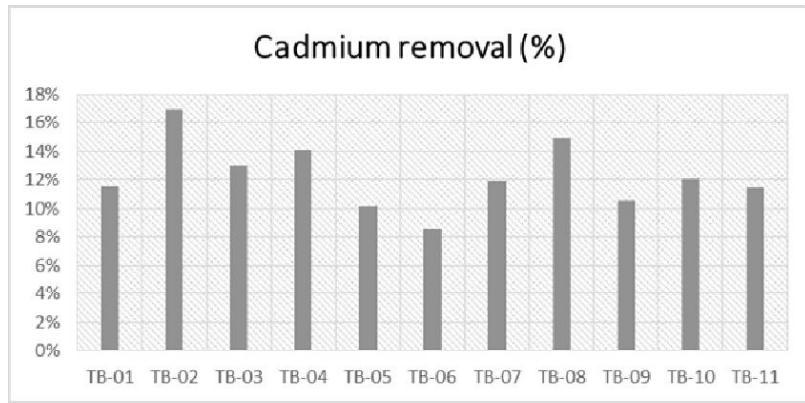

Fig. 4. Cadmium removal efficiency after batch adsorption test

To determine mechanism of cadmium adsorption, the cation concentration $\left(\mathrm{K}^{+}, \mathrm{Na}^{+}, \mathrm{Ca}^{2+}\right.$, and $\left.\mathrm{Mg}^{2+}\right)$ and acidity of solution after batch adsorption test were analysed. Based on experiment by Zhou et al. [19], the primary adsorption mechanism of char on cadmium was cation exchange interaction. In this experiment, cation content was measured to gain similar results. The results are shown in Fig. 5 below, which indicate the exchanged cation content with cadmium ion from hydrochar into solution. Higher content of cation shows higher cation availability for heavy metal adsorption on hydrochar surface and also the potential of cadmium adsorption. The highest cation content is shown by TB-05 (1.05 $\mathrm{mmol} / \mathrm{g}$ ). The chart shows that addition of acid with similar process condition improved the cation content on hydrochar, as showed by TB-09 $(0.2954 \mathrm{mmol} / \mathrm{g})$ to TB$10 \quad(0.3294 \mathrm{mmol} / \mathrm{g})$. Generally compared to its adsorption capacity from Fig. 7, both charts show similar trend of increase. The result indicate that overall cadmium adsorption was affected by the cation content of hydrochar.

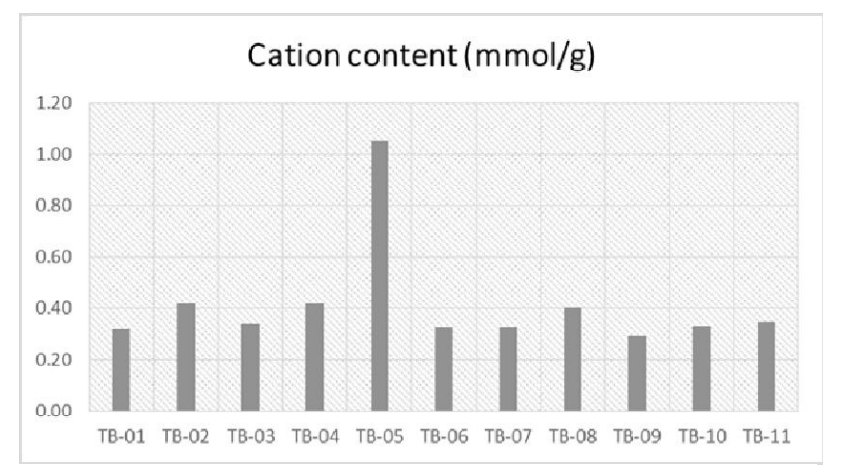

Fig. 5. Exchanged cation content after batch adsorption test

The effect of acid addition on tested solution after batch adsorption test was also investigated. The filtrate after adsorption test was analysed with $\mathrm{pH}$ meter before analysis with ICP. The results are shown in Fig. 6. The black line shows the original acidity of solution (5.728) before adsorption test. In general, the samples with acid addition showed trend of decreased acidity, especially at high acid ratio such as TB-02 (5.728 to 4.795) and TB04 (5.728 to 4.844). However there is no significant decrease in acidity, which shows that the hydrochars produced with acid addition should not affect the acidity of original solution significantly after adsorption process. There were also several samples with no acid addition that decrease the acidity of solution. This shows that in the hydrothermal reaction, certain acid chemical might be produced and decrease acid solution. However, further analysis should be conducted to determine its effect on hydrochar characteristics.

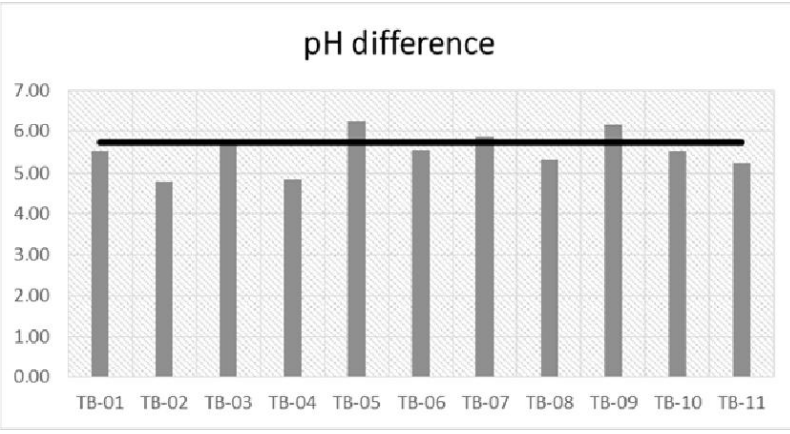

Fig. 6. Effect of acid addition on batch adsorption test solution 
FTIR and SEM will be conducted to get further insight of functional groups presented on hydrochar surface before and after adsorption test, as well as to investigate effect of acid addition to functional group content in hydrochar.

\subsection{Comparison with commercial activated carbon}

The performance of hydrochar on cadmium adsorption was compared with two types of commercial activated carbon. The granular and powdered activated carbon were used to investigate the effect of particle size in cadmium adsorption. The purpose of this comparison was to determine the potential of tree branches hydrochar to substitute CAC on cadmium adsorption. The results were shown in Fig. 7 below. In average, the hydrochars adsorption capacity was equal and several samples have higher capacity, such as TB-02 and TB-08. The results were showing promising potential of hydrochar, processed with certain condition to substitute CAC. The highest adsorption capacity was TB-02, which was processed at $200{ }^{\circ} \mathrm{C}, 30$ minutes, and with $50 \%$ acid. However, compared to similar condition with no acid addition (TB-01), the adsorption capacity also shows equal performance compared to CAC. At commercial scale, it might be possible to produce hydrochar without utilizing acid in its process and use it as substitute of $\mathrm{CAC}$, due to its similar adsorption performance.

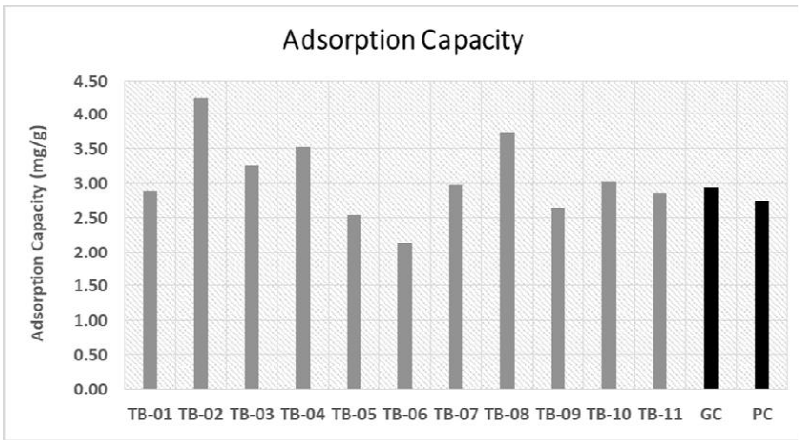

Fig. 7. Comparison of hydrochars (grey bar) and CAC (black bar) adsorption capacity

\section{Conclusion}

From the results shown by analysis conducted in this research, it can be concluded that addition of acid in HTC process gives effects on the surface properties of hydrochars. Bigger quantity of acid caused smaller hydrochar yield and BET surface area of hydrochar, but higher cations content can be produced. Based on this research, hydrochar produced with low temperature (200 ${ }^{0} \mathrm{C}$ ), short time (30 min.) and high acid ratio (50\%) has the highest cadmium adsorption capacity. Thus the hydrochar product with acid addition has better heavy metal adsorption capacity. However, further analysis will be conducted to investigate the adsorption mechanism of cadmium into hydrochar better. OFG test will also be conducted to further examine adsorption mechanism and its effect on adsorption capacity.

The cadmium adsorption capacity of tree branches hydrochar and CAC have been compared and the results showed that hydrochar has comparable and potentially more adsorption capacity than CAC. It can be concluded that tree branches hydrochar has potential to be substitute for CAC in terms of cadmium adsorption. With further development, this research might resulted in new and renewable adsorbent for heavy metals that can be applied for wastewater treatment facility and commercialized as staple substitute for CAC.

\section{References}

1. TM Abdel-Fattah, ME Mahmoud, SB Ahmed, MD Huff, JW Lee, S Kumar. Biochar from woody biomass for removing metal contaminants and carbon sequestration. $J$ Ind Eng Chem. The Korean Society of Industrial and Engineering Chemistry 22, 103-109 (2015)

2. I Ali. The quest for active carbon adsorbent substitutes: Inexpensive adsorbents for toxic metal ions removal from wastewater. Sep Purif Rev 39(34), 95-171 (2010)

3. L Axelsson, M Franzén, M Ostwald, G Berndes, G Lakshmi, NH Ravindranath. Perspective: Jatropha cultivation in southern India: Assessing farmers' experiences. Biofuels, Bioprod Biorefining 6(3), (2012)

4. ND Berge, KS Ro, J Mao, JR V Flora, MA Chappell, S Bae. Hydrothermal Carbonization of Municipal Waste Streams. Environ Sci Technol 45, 13:5696-5703 (2011)

5. W Ding, X Dong, IM Ime, B Gao, LQ Ma. Pyrolytic temperatures impact lead sorption mechanisms by bagasse biochars. Chemosphere. Elsevier Ltd. 105:68-74 (2014)

6. J Fang, B Gao, AR Zimmerman, KS Ro, J Chen. Physically (CO2) activated hydrochars from hickory and peanut hull: preparation, characterization, and sorption of methylene blue, lead, copper, and cadmium. RSC $A d v$. Royal Society of Chemistry 6, 30:24906-24911 (2016)

7. B Hu, K Wang, L Wu, SH Yu, M Antonietti, MM Titirici. Engineering carbon materials from the hydrothermal carbonization process of biomass. $A d v$ Mater. 22, 7:813-828 (2010)

8. H Li, X Dong, EB da Silva, LM de Oliveira, Y Chen, LQ Ma. Mechanisms of metal sorption by biochars: Biochar characteristics and modifications. Chemosphere. Elsevier Ltd. 178:466-78 (2017)

9. H Lu, W Zhang, Y Yang, X Huang, S Wang, R Qiu. Relative distribution of $\mathrm{Pb}^{2+}$ sorption mechanisms by sludge-derived biochar. Water Res. Elsevier Ltd. 46, 3:854-62 (2012)

10. A Jain, R Balasubramanian, MP Srinivasan. Production of high surface area mesoporous 
activated carbons from waste biomass using hydrogen peroxide-mediated hydrothermal treatment for adsorption applications. Chem Eng J. 273:622-629 (2015)

11. JH Park, YS Ok, SH Kim, JS Cho, JS Heo, RD Delaune, DC Seo. Competitive adsorption of heavy metals onto sesame straw biochar in aqueous solutions. Chemosphere. 142:77-83 (2016)

12. JT Petrovi, MD Stojanovi, MS Petrovi. Alkali modified hydrochar of grape pomace as a perspective adsorbent of $\mathrm{Pb}^{2+}$ from aqueous solution. 182:292-300 (2016)

13. Z Tang, Y Deng, T Luo, Y Xu, N Zhu. Enhanced removal of $\mathrm{Pb}$ by supported nanoscale $\mathrm{Ni} \mathrm{Fe}$ on hydrochar derived from biogas residues. 292:224232 (2016).

14. L Wang, Y Guo, B Zou, C Rong, X Ma, Y Qu, Y $\mathrm{Li}$, Z Wang. High surface area porous carbons prepared from hydrochars by phosphoric acid activation. Bioresour Technol. 102, 2:1947-1950 (2011)

15. Z Wang, G Liu, H Zheng, F Li, HH Ngo, W Guo, C Liu, L Chen, B Xing. Investigating the mechanisms of biochar's removal of lead from solution. Bioresour Technol. Elsevier Ltd. 177:308-317 (2015)

16. Y Xue, B Gao, Y Yao, M Inyang, $M$ Zhang, AR Zimmerman, KS Ro. Hydrogen peroxide modification enhances the ability of biochar (hydrochar) produced from hydrothermal carbonization of peanut hull to remove aqueous heavy metals: Batch and column tests. Chem Eng J. Elsevier B.V. 200-202:673-680 (2012)

17. L Zhou, Y Liu, S Liu, Y Yin, G Zeng, X Tan, X Hu, $X \mathrm{Hu}, \mathrm{L}$ Jiang, $\mathrm{Y}$ Ding, $\mathrm{S}$ Liu, $\mathrm{X}$ Huang. Investigation of the adsorption-reduction mechanisms of hexavalent chromium by ramie biochars of different pyrolytic temperatures. Bioresour Technol. 218:351-359 (2016)

18. N Zhou, H Chen, J Xi, D Yao, Z Zhou, Y Tian, X Lu. Biochars with excellent $\mathrm{Pb}(\mathrm{II})$ adsorption property produced from fresh and dehydrated banana peels via hydrothermal carbonization. Biores Tech. 232:204-210 (2017)

19. Z Zhou, Z Xu, Q Feng, D Yao, J Yu, D Wang, S Lv, $\mathrm{Y}$ Liu, $\mathrm{N}$ Zhou, M Zhong. Effect of pyrolysis condition on the adsorption mechanism of lead, cadmium and copper on tobacco stem biochar. $J$ Clean Prod. Elsevier Ltd. 187:996-1005 (2018) 